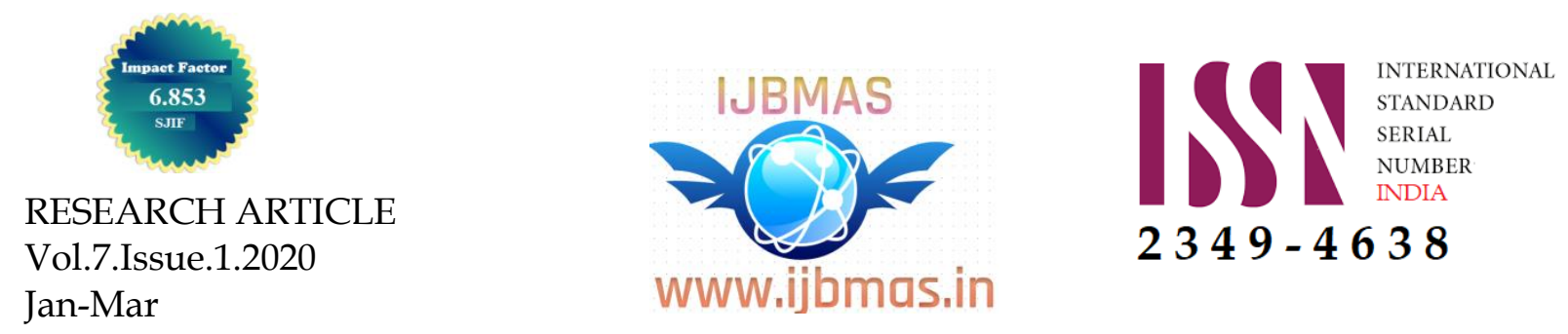

INTERNATIONAL JOURNAL OF BUSINESS, MANAGEMENT AND ALLIED SCIENCES (IJBMAS)

A Peer Reviewed and refereed Journal

\title{
THE CASE STUDY AS A STRATEGY, METHOD AND OBJECT OF RESEARCH IN ADMINISTRATION
}

\author{
Dr.KHALIFA ABDALLA KASHTIA ${ }^{1}$, \\ Dr. ARRASHEID ABDUALLAH AL ARRASHEID², \\ OSAMA MOHAMED ELSHAREF ${ }^{3}$ \\ ${ }^{1}$ Faculty of commerce Tarhuna - Azzaytuna University - Libya \\ Email:Kshtia73@gmail.com \\ ${ }^{2}$ College of Commerce and Political Science - Sebha University- Libya \\ Email:Alrshedabdhal@gmail.com \\ ${ }^{3}$ Authority of Natural Science Research and Technology - Libya \\ Email:Osamasharif.2015@gmail.com \\ DOI: $\underline{\text { 10.33329/ijbmas.7.1.56 }}$
}

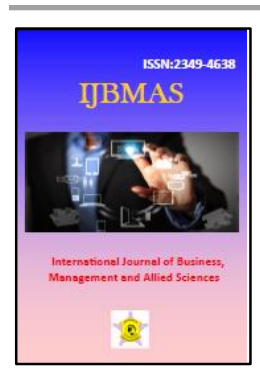

\begin{abstract}
Research strategies, with hypothetical guidance deductive-measuring, quantifying, testing variables and generalizing results-are dominant in administrative sciences. However, it has been found that administrative knowledge-product of generalization based on statistical inference- "does not always work," due to the very specific conditions and situations of organizations across different contexts and time travel. That is, we find knowledge gaps to understand specific conditions and situations of the different expressions of the administrative phenomenon, so case studies are relevant. The case studies correspond to the intensive analysis of particularities of situations and behaviors in units constituted by a small number of individuals, groups, organizations, programs, processes, or organizational positions. However, it is denoted that many of the research findings that are reported as products of the case studies have different implications and connotations derived in turn, from the different interpretations of their authors on the concept, design and implementation of a study of case. This paper discusses the case study as a strategy, method and object of investigation.
\end{abstract}

Keywords: Case study, administration, investigation

\section{Introduction}

The case study is a reliable research tool and method when it is designed, implemented and systematized, rigorously, following the procedures of a research project. In research oriented towards 
the construction of Management Theory, research designs whose basis is quantitative measurement with emphasis on the statistical analysis of sample information have been used, predominantly. However, also, when reviewing the literature on research in the Administration, a significant number of studies that have been developed as case studies are denoted. The case study is a form of empirical research, which relies on multiple sources of information, and is relevant to elucidate aspects that are not evident between the phenomenon of interest and its context. The case studies correspond to the intensive analysis of particularities of situations and behaviors in units constituted by a small number of individuals, groups, organizations, programs, processes, or organizational positions.

Case studies are becoming increasingly popular among academics and students of educational administration programs and organizational studies, and also, as a means of obtaining information to find answers to the dilemmas of administrators of various organizations. . The rationale for using the case study format has been made under the premise that it has been found that knowledge in these areas-product of generalization from statistical inference- "does not always work," due to conditions and situations very specific organizations through different contexts and time travel. That is, there are requirements to analyze and understand in depth each "case" emerging in the Administration of Organizations.

Indeed, during the last 25 years, case studies have been widely used to carry out Administration research in specific business contexts. For example, the interrelationships between different aspects of: marketing and customer satisfaction; the role of accounting in administrative control; the role of strategy in the pharmaceutical industry Case studies make it feasible for administrative science researchers to identify holistic and significant characteristics of real-life events in the conduct of organizations. As we mentioned before, the exploration spectrum of the case study is broad, for example, they are oriented in the description and analysis of decision-making both in individuals and in organizations, processes and events. With the Case study is possible to analyze and respond to the challenges facing the administration of organizations in the current contexts of greater diversity and inter-organizational competence. This methodological proposal has comparative advantages to analyze and find answers, for example, to the challenges for the design of strategies faced by managers involved in companies that compete in the current context of globalization. Then, the case studies are suitable for analysis. Decision-making and strategic thinking mapping.

However, it is denoted that many of the research findings that are reported as products of the case studies have different implications and connotations derived in turn, from the different interpretations of their authors on the concept, design and implementation of a study of case. The purpose of this paper is to make a brief review on the subject of the case study as a strategy, method and object of research as an adjunct in the construction of knowledge for Management Theory.

\section{Objectives}

- Briefly describe central ideas about the case study as a strategy, method and object of research in the Administration of organizations.

- Review different views of authors who have written about the case study..

\section{Literature Review and Case Study Discussion}

In addressing this issue it is necessary to distinguish the two meanings that are conferred on the case in the context of the studies, investigations and teaching of the Administration.

We refer first to the case study, which is also called a case or case study; where a real or fictitious case is designed for teaching purposes and to promote the competence of students to make decisions when facing administrative dilemmas in different organizational, planning, direction and control situations of organizations' resources and processes. In this type of cases it is used, and analyzes information to suggest courses of action referenced in the theory of the existing Administration. That 
is, in the case, case study or case study only the application of the Administration is recreated. Fundamentally, it is a pedagogical device for the training of future administrators

On the other hand, we have the case study, central theme of dissertation in this work. The case study is a tool for formal and systematized research, which is oriented towards the generation of knowledge investigating situations of Administration in specific contexts that are not enough to be explained by the Administration Theory in force at the time of occurrence of the phenomenon. The case study seeks to describe, explain and understand relationships, interactions, behaviors, processes that "escape" ideas, concepts and theories "Generally accepted" by the Administration. With this precision, we reiterate our dissertation is about the case study.

\section{Case Study strategy, method and object of investigation}

There are different views on the case study. This debate dates from 1935 when academics from the Chicago School - followers of the case study as a research method - clashed with academics from Columbia University - followers of the "scientific method" and detractors of the case study. Today's academics still have different perspectives on the case study and, in that line, most have adopted it with different conceptions. For some, the case study is a research method, which can be a vehicle to test or even to build theory; others consider it as a research strategy; and others assume that it is only a choice of the object of study.

\section{Case Study, research strategy}

It is a research strategy whose resulting information can help in the decision-making process about "out of the ordinary" situations in the conduct of organizations. It is a strategy guided by three central research questions:

When? How? And because? The premise is the in-depth understanding of the case. To effectively provide information from an in-depth study, the case study involves its construction based on the integration of all kinds of information collected through different strategies; It is an appropriate research strategy to explore, describe and explain complex and changing situations and realities that emerge during the Administration of organizations.

It is a strategy because we define how and why we will carry out research activities, at what times we will make observations, surveys, among others. Indeed, in the field work, the case study is a strategy of integration of key elements, emerging from different sources of information, for example, from the interview, observation and documentary research; collecting all kinds of allusive data to understand the situations, behaviors, experiences of the participants and the context of the case analysis unit. It is also a strategy to identify, record, organize, analyze, interpret and synthesize information to understand the uniqueness of the case with its consequences and results in decision making. It is a strategy and, among its several advantages: the recognition of the complexity of the Administration of organizations stands out, the information it provides can be reinterpreted later, and the research results are presented in a more accessible way for a greater number of people.

The case study as a strategy makes the iterative analysis of information feasible within the context of development and application of events, processes and behaviors; By way of illustration, for example, we assume that we are interested in knowing how the process of organizational communication within a company is, so we will record observations in the natural environment where this process occurs: in the weekly planning and evaluation meetings, the dissemination of the forms of operationalization of management decisions in different areas and departments, among others.

It is important that the researcher has skills in the construction of the case study to "read" the information during the analysis, that is, to have inductive capacity to interpret the case. Also, it is recommended that, given the large volume of information that is collected, appropriate procedures be established to organize, systematize and categorize the records of observations on the case. This 
research strategy gives us the opportunity to generate knowledge on the basis of recording unique events in the administration and, this body of information can be used to analyze and interpret situations similar to the conditions under which the study was conducted.

\section{Case Study, research method}

According to the different disciplines in which the case study is used, we find a wide variety of views on its definition as a research method and its purpose. Likewise, we identify that they are implemented according to the epistemological orientation of the researchers, therefore, they are constructed by quantitative, qualitative methods or by a combination of these two perspectives. That is, they have been used as exploratory, descriptive and explanatory studies and interpretative. Then, depending on the concept of objective or subjective reality that the researcher has, it will be the choice and purpose of the case study.

Also, in the case studies we can integrate the positivist and interpretative perspectives for a better understanding of the observed situations. In other words, we can undertake case studies with a deductive approach, linked to the proof of the existing administrative theory; and the case studies of inductive orientation towards the formulation of theoretical propositions or theoretical construction. Through this method of the case study it is feasible to derive consistent contributions in the administrative sciences.

The case study is relevant as a consistent method of investigation, particularly when research with a holistic approach and situational depth is required. Indeed, the case study as a research method, with a holistic and in-depth approach, is used in many studies of the social sciences within which we find several investigations carried out in our field of Administration and organizational studies.

Research through the case study method allows the exploration and understanding of complex situations that arise and, essentially, when we find that the ideas and concepts of Management Theory do not "operate" under certain conditions. They are "cases" to investigate how and why certain characteristics of processes, interrelations, interactions, consequences and results of decision making are had. Regarding the usefulness of the case study as a method of investigation, there are ideas found, with respect to the number of units of analysis involved in the study: a set of "cases" or a "case?"

On the one hand, it is considered that the case studies designed and conducted as multiple case studies, through systematized, inductive and iterative procedures, can be useful schemes for theoretical construction in the Administration. With this expectation of research, the study of as many cases as possible and of course should be ensured, allowing the researcher to maintain a good level of depth of analysis in order to achieve the validity and credibility of the theoretical propositions. These are multiple case studies, multi case studies or collective case studies mentioned by Stake (2005).

On the other hand, there are opinions that support the case study in its meaning: "case" as a simple unit of analysis, which must be worked exhaustively and holistically, that is, within the maximum expression of depth in the understanding of a particular social situation of events of Administration of the organizations. In this line would be the intrinsic and instrumental case studies.

Critics of the case study, as a method of investigation, question its high dependence on an individual case that consequently provides hardly generalizable conclusions. However, if the parameters of interest are previously defined and applied, observing rigor during the investigation process, the validity and credibility of the findings are ensured, then the case study may be acceptable. In this line, the generalization that is made either of an individual case or of a multiple case, is in terms of theory and not of the population studied.

Fundamentally, the case study method has two research purposes: one, the understanding of the situations, conditions and expressions of the phenomenon under study; and two, develop theoretical approaches to explain what happens in the regularities found. Through this method, focused on the 
detailed and intensive analysis of situations, it is feasible to obtain knowledge about the phenomena that are under study in Administration.

The case study as a research method provides organized and systematic ways to observe and record the events of the administrative phenomenon at different levels and with varying degrees of complexity.

The collection of information is oriented towards the structured collection of evidence in the field using multiple sources of information: documentary research, interviewing actors, observing interactions, taking notes, recording situations, comparing processes, behaviors, consequences and results. Simultaneously, with the collection of information we carry out the process of analysis, gradual, continuous, throughout the entire period assigned for research.

The analysis focuses on the comparison and constant contrast of findings on the interrelationships between different situations in order to identify critical elements for decision making with its consequences and results; It is therefore important to identify interrelations, concepts and explanations and tentative theoretical implications. Also, our analysis will be directed from the individual cases analyzing the regularities found, and involving more similar cases we will denote both regularities and differences; In this incremental line of focus, we can move towards theoretical approaches that can be generalizable. The Validity and credibility of our findings will be given to the extent that we involve multiple evidences and multiple sources of information in our analysis.

Likewise, when we use this option as a research method, it is advisable to use a set of cases or multi-cases to, from the analysis, derive relevant findings about similar situations and behavior patterns that transcend beyond individual cases. It should be mentioned that it is not so important to involve a certain number of cases, but the most important thing is how these cases are addressed or approached. Through the process to investigate the multi-cases it is feasible to denote and identify the regularities or similarities between the cases involved in the investigation as well as the interrelationships between the different situations investigated, with that, the emerging theory will be more firm and generalizable.

Also, the case study according to the dimension of the research time can be bounded as transverse and longitudinal, which will depend, fundamentally, on the purposes of the study. In the cross-sectional modality, the study focuses on a single brief period of recording time and contextual analysis of the phenomenon. The longitudinal case study involves a systematic way of recording evidence and expressions about events, over a period of time with several moments of observation; the approach is to record what happens in different situations during the investigation period. The possibilities of application are wide, for example, studies of customer behavior and consumer preferences at different times allow changes and trends to be identified over time; with that, the resulting information can help in the decision-making process to improve the processes of production, quality and supply of goods and services. The case study as a research method provides ways of observing any phenomenon embedded in a set of information.

In the construction of the case study it is important to make a systematic record of the evidence obtained by the set of information collection procedures. From the collection of the first evidences we will proceed to the gradual analysis, in an iterative process collection-simultaneous analysis; This process will be based on triangulation strategies and the constant comparative method. The findings will be contrasted with a theoretical framework inherent in the research question and objective.

In the Administration, the case study, as a research method, is useful to analyze, interpret and understand different expressions of behaviors, interactions, interrelations, consequences and results. It may be, for example, that we are interested in understanding how managers use decision-making strategies, at this level of inquiry, it is an exploratory case study and would aim to identify propositions and hypotheses about the administrative phenomenon. At a next level, looking for a greater knowledge 
on the subject we also consider how, also, we propose to know how much they use strategies and what strategies, then, we operate a descriptive case study, and we focus on the generation of ideas and descriptive concepts At a higher level, we have the explanatory case study, and we wonder how, what strategies, how much, why and identify the consequences and results of decision making; At the latter level, the case study provides explanatory ideas, concepts and theory; We explain what, how, why and under what circumstances the expression of the administrative phenomenon occurs. Thus, the purposes of the case study can be basically of three types: exploratory, descriptive and explanatory.

On the credibility, validity and reliability of the findings of the case study, these will be given by the researcher's skills and competencies to design and implement, in terms of quality control, the development of the collection-analysis research process, the degree of consistent integration of constructs, clarity of relationships and interactions identified, and relevant saturation of information through triangulation strategies and constant comparative method; the interpretations and judgments must be supported both in the empirical information and in propositions inherent in the Theory of Administration. That is, it is advisable to describe, reflect and interpret the evidence or facts derived from the phenomenon; and communicate the findings in theoretical terms. In this line, it is mentioned that the researcher performs the exercise of communicating his findings in a balanced way, without falling into the extremes of the simple explanation and the complicated explanation.

\section{Case Study: the case, object of investigation}

As an object of investigation, the case is the expression of a unique phenomenon that departs from the general conceptualization of the Administration and represents a dilemma for the administrator. In the event of the administrator's dilemma, it is necessary to seek information to decide courses of action. The available information is collected, analyzed and denoted that complementary information is needed, it is then that a case study is chosen. The study is undertaken by the administrator or uses a researcher. In both cases, the sequence of the investigation process is broken down from the administrator's dilemma. Then, the case is the object of investigation, which when applying a set of procedures and strategies (research method and strategy) - for the investigation and systematization of evidence on the interrelations and interactions between the different aspects that configure the uniqueness of the Case in its specific context of occurrence - is the construction of the study: the case study.

Thus, the administrator's dilemma is the real problem and the object of investigation; it is the case that is constructed, which begins with the initial questions and concludes with the investigation report; then, the orientation is the what, for what, why, how, where, from where, since when and with what, of the object of investigation. The case is defined and constructed based on a theoretical problem, is to make "the data speak" to be able to make the problematization directed to the generation of knowledge about the case as an object of investigation in the Administration. Then then, the case as an object of investigation is the constructed representation of the administrative phenomenon.

\section{Methodological sequence of the Case Study}

In the case study design, it is pertinent that a group of minimum elements necessary for its implementation be covered: the research questions, the proposals / hypotheses, the analysis units, the information-propositions / hypothesis relationship logic and the criteria for interpret the findings. The case is subject to investigation through a structured and sequential process in which it is pertinent to define at least six key elements for the construction of the study (Figure 1) in the Administration of the organizations: Administrator's dilemma, problem statement and case definition, design of the case study, collection-analysis of information, contrast of results with the Theory of Administration and, report and presentation of the case study. 


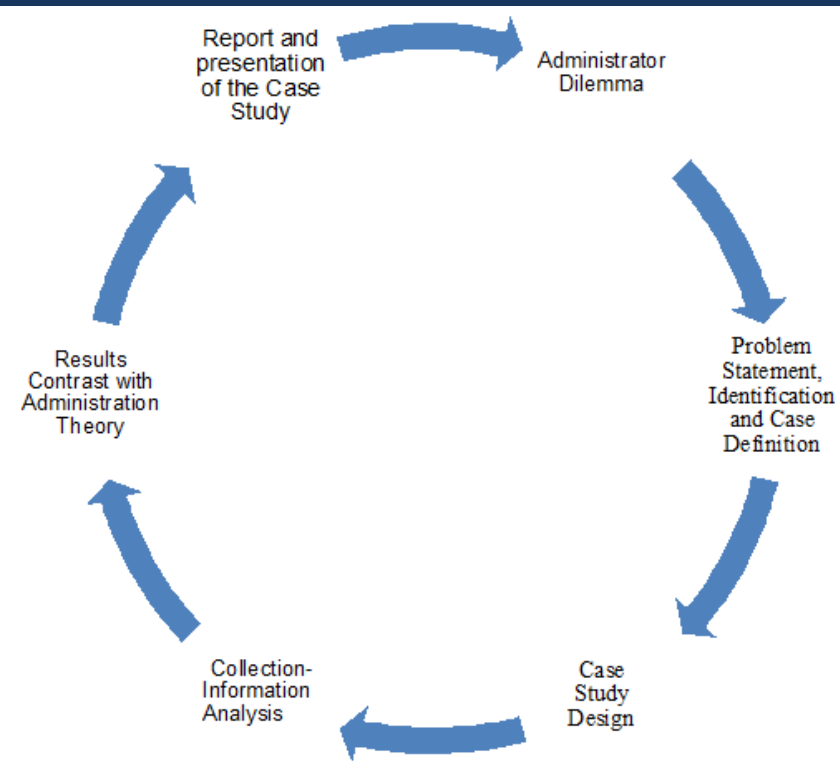

Figure 1. Construction of the case study in Organizational Administration

\section{Source: self made}

Several investigations carried out in the Libyan context have used the case study as a method, strategy and object of investigation in the Administration of Organizations. Indeed, the case study has been used to investigate how and why certain administrative phenomena occur that cannot be understood through the existing ideas, concepts and theories that support the Administration.

These emerging cases correspond to specific situations, processes, interactions and behaviors. We know that the Administration theory predominantly has its support and application in large companies and, when we have a certain "unique" decision situation of a small company then, the researcher places his object of study in the sector of "smaller" organizations For example, he chooses to carry out his case study in the MSMEs sector. Here, we illustrate with a case study of a company in the MSME sector in the libyan textile industry; Its objective was to analyze the company's actions to face Chinese competition and how these managerial actions were working; Among the benefits of the study, it was identified that in the form of administration the potential of the advantage of flexibility and agility in decision-making was not considered, which would be solved with a strategic planning scheme. The limitation of the study lies in the uniqueness of the situation studied.

Other researchers find their field of action in "not so small organizations" and are stationed in the field of SMEs; and they carry out a qualitative case study whose objective was to analyze which Human Resources Administration practices facilitate (and how) entrepreneurial behaviors in SMEs; the case is a multicast with three different companies in activity and in entrepreneurial orientation; Among the benefits of the study, they identified that positive relationships, a favorable working environment, a favorable attitude towards risk and a management style favor entrepreneurial behavior in SMEs, and make a difference with respect to large companies, which apply formal programs of promoting that behavior; As limitations of the study we find its findings, because it is a qualitative study, they remain at the level of theoretical propositions depending on the specific situations encountered.

It is also of interest for research to explore what happens with technological innovation in some industrial sector, for example, in the manufacturing sector. Here we have that a multi-case study was constructed based on the information of an investigation made up of 17 Libyan companies oriented to the identification of the characteristics of technological innovation processes in manufacturing companies; The contributions of this case study consist in the identification of competitive, technological and innovation profiles in Libyan companies, their comparison with similar events within the Libyan business context, as well as their differentiation from the technological innovation processes 
that occur in the developing countries; The limitations of this investigation are limited to its dependence on the time and circumstances in which the events were observed.

Also, in the face of competition, strategic decisions are required, how are decisions made? We found a multiple case study conducted in the oil production sector in the Central Region of Libya , it was implemented to determine the factors that influence competitiveness and impact the strategic behavior of the participating companies of this sector; the contributions of the study entail the detection of four factors of resources and capacities, five factors of the industry level, and the description of the process of configuration of the strategic behavior; The findings are specific to the problem found during the investigation. In the field it is grown, produced, marketed, organized and, how is it managed? Similarly, to concur in the analysis of the problem-expired portfolios, loss of control of the productive processes, among others-faced by the peasant companies of a coffee organization, a qualitative longitudinal case study was designed and implemented, composed of nine agricultural social enterprises in the State of Libya, which aimed to identify the impact of the administration aspects on the development, performance and survival of these peasant companies; The basic questions of the study focused on finding answers to how they were being administered and, once the aspects of how were known, simultaneously knowing why certain types of decisions were made; Among the benefits of the study, the functions of the administrative process were characterized and the properties and dimensional ranges of the administration of these companies were identified: context perception, problem management, organizational crisis, and organizational survival; The limitations of this study include the difficulty in tying the technical management solution with the political orientations of the peasant decision makers or what about management techniques in transnational companies? Another qualitative multicast study made up of two multinational companies was oriented in the analysis of how the Kaizen scheme is implemented in the Libya context and in the comparison with the theoretical platform of the concept; the processes of continuous improvement are examined both operational and strategic and found gaps between the implementation of this management technique and what is established by the Kaizen theory; the contributions of the study express theoretical constructions on the nature of the implementation of this technique, register elements of confusion in the understanding of the concept and account for differences and similarities, between Libya and other countries, with respect to the implementation of Kaizen; The authors recognize that their findings cannot be generalizable.

In this brief journey on some research through the case study, we find that the collection-analysis of intensive and exhaustive information enables researchers to deepen the description and understanding of the administrative phenomenon in specific contexts of occurrence. Likewise, the richness of the findings lies in their theoretical contributions, that is, in the generation of knowledge that increases the descriptive and explanatory collection of administrative sciences and, at the same time, orientations are generated to support management activity in the business world. Also, we found that the scope of the results, in the different studies, are similar in terms of description, explanation and understanding of the administrative phenomenon under investigation; they have high correspondence and dependence on the situations encountered during the study. Therefore, the findings are not generalizable.

\section{Conclusions}

1. The case study is a method and a research strategy: It is a methodological choice when we opt for the adoption of the case study, seeking the feasibility of our research addressing the detailed analysis of a scenario, event, individual, group or organization. Then, its construction will be based on a research strategy for data collection consisting of the broad exploration of the network of information sources on the topic; Likewise, the analysis and interpretation of the information will be through a "funnel" strategy, that is, the analysis from the broadest context to descend in the focus of study. The construction of the case study requires the use of eclectic data with information obtained through the 
observations of the organization, its documentary records, and interviews with members and former members of the same, complemented with all kinds of information that the researcher considers pertinent. Therefore, it is convenient to weigh whether there is sufficient data sources. Also, consideration of the temporal dimension of the study is important; and in this sense, the concentration of effort in a single case or in a multiple case allows to trace the development of events or organizational situations over time. With the capture of the organizational biography, the identification of processes and organizational changes are clarified. The findings of the case study can be elements to prove theory or as a source of hypotheses or theoretical propositions.

2. The case study is an object of investigation: When we find that existing knowledge about the administration of organizations "does not always operate" in particular situations or behaviors, the researchers - under the consideration that generalization cannot be a flat tab - choose to reconsider their choice of the object of study. Then, they choose to approach their object of study as a "case." Thus, the case study in Administration of organizations can be focused or focus on the detailed analysis of a particular department or operational area, a group of people from that area, certain activity, situation, behavior or a combination of foci. study. Thus the object of study is delimited, it is possible to place a greater emphasis on a certain aspect of interest of the researcher, that is, the object of study is reduced to make it "manageable" - areas, groups, programs with a concentration of subjects - without avoiding the organizational whole.

For all the above, we can conclude in a general way, that when the researcher opts for the case study, he has three orientations: he makes his choice of the research method and strategy, and also does it in terms of selection and construction of the object of study. These inquiry orientations are not mutually exclusive. We do not forget to point out that the design and implementation must be done with the necessary rigor for its proper construction. The resulting findings must be presented with a clear and precise definition of their scope and limitations. The results of a simple case study are applicable to the situations, contexts and times in which the research was done. Multiple case studies can aim to make theoretical propositions, since it is assumed that they were constructed by integrating several cases where the same analyzes and interpretations were repeated and shared. In this multiple design it is interesting to apply the inter-site comparison (Hernández-Pólito 2002). With that, it is feasible to find differences and regularities, hence the saturation of the findings and with it, expand or challenge the existing theory.

\section{References}

[1]. Abughalia, Wessam, et al; Impact of International Economic Embargoes on the Libyan Foreign Trade; International Journal of Academic Research in Economics and Management Sciences; June 2012, Vol. 1, No. 3; ISSN: 2226-3624

[2]. Al Arabiya News; No 'major' role for NATO in post-Qaddafi Libya, says alliance chief; 06November 2011; http://www.alarabiya.net/articles/2011/11/06/175766.html; last accessed 24July 2013

[3]. Arab Organization for Human Rights; Report of the Independent Civil Society FactFindingMission to Libya; http://www.pchrgaza.org/files/2012/FFM_Libya-Report.pdf; last accessed 24 July 2013

[4]. Benamer, Hani; Healthcare System in Libya - Factual Report; January 2012;http://www.libyanhealthservices.com/uploads/1/0/3/7/10376524/healthcare_system_i n_libya_factual_report_2012.pdf; last accessed 2 July 2013

[5]. Bertelsmann Stiftung; BTI 2012 - Libya Country Report; Gütersloh: Bertelsmann Stiftung,2012;http://www.btiproject.de/fileadmin/Inhalte/reports/2012/pdf/BTI\%202012\%2 0Libya.pdf;last accessed 24 July 2013 
[6]. Beynon-Davies, P. 1994. Information Management in the British National Health Service: the pragmatics of strategic data planning, International Journal of Information Management, 14 , 1994, pp. 84-94

[7]. Black, Ian; Libyan revolution casualties lower than expected, says new government; TheGuardian; 8 January 2013; http://www.guardian.co.uk/world/2013/jan/08/libyanrevolutioncasualties-lower-expected-government last accessed 24 July 2013.

[8]. Blasius, Michael P.; Caring for Libyan War Wounded in Germany and Austria Benefits of astructured system of case management; Almeda;

[9]. http://www.health.ghorfa.de/fileadmin/inhalte/2011/Sprecher/Pr\%C3\%A4sentationen/Mic hael_Blasius_-_almeda.pdf; last accessed 24 July 2013

[10]. Catala I. ; Effet collatéral de la crise Libyenne: alerte aux bactéries multi-résistantes;MEDSCAPE France; 22 May 2012; http:/ / medscae.fr/ / article/1404817/; last accessed 30 July2013

[11]. Chivvis, Christopher S. et al; Libya's Post-Qaddafi Transition, The Nation-Building Challenge;RAND; 2012; ISBN: 978-0-8330-7838-4;

[12]. Collis, D.J. y T. Smith (2007). Strategy in the 21st Century Pharmaceutical Industry: Merck \& Co. and Pfizer Inc. en Harvard Business School, Case 707-509, noviembre 2007.

[13]. Corbin, J. y A. Strauss. (2012). Basics of Qualitative Research: Techniques and Procedures for Developing Grounded Theory. 3a Ed. SAGE.

[14]. Cousins, Michel; Health Minister stands up to her critics: interview with Dr. Fatima Hamroush;Libya Herald; 13 August 2012; http://www.libyaherald.com/2012/08/13/healthministerstands-up-to-her-critics-interview-with-dr-fatima-hamroush/; last accessed 30 July 2013

[15]. Denzin, N. K. y Y. S. Lincoln. (2012). The discipline and practice of qualitative research, en Denzin, N. K. y Y. S. Lincoln. (Eds), The SAGE Handbook of Qualitative Research.4a Ed. SAGE Publications.

[16]. Dingwall, R. 1997. Accounts, interviews and observations in G. Miller . y R. Dingwall R. (Eds.), Context and Method in Qualitative Research, Thousand Oaks, CA: Sage Publications, pp. 51-65.

[17]. Dominici, G. (2010). Customer Satisfaction in the Hotel Industry: A Case Study from Sicily, en International Journal of Marketing Studies, Vol. 2, No. 2; Noviembre 2010

[18]. Doolin, B., L. Burgess y J. Cooper (2002). Evaluating the use of the Web for tourism marketing: a case study from New Zealand, en Tourism Management, Volume 23, Issue 5, October 2002: 557561

[19]. Dubé, L., and Paré, G. 2003. Rigor in Information Systems Positivist Case Research: Current Practices, Trends, and Recommendations, MIS Quarterly (27:4) 2003, pp 597-636.

[20]. Dyer, W. G. y A. L. Wilkins. 1991. Better stories, not better constructs, to generate better theory: a rejoinder to Eisenhardt, Academy of Management Review, Vol. 16 No. 3. pp. 613-619.

[21]. Eisenhardt, K. M. (1989). Building Theories from case Study Research, en Academy of Management Review, Vol 14, No. 4, octubre, 1989, 532-550: The Academy of Management

[22]. Eisenhardt, K. M. y M. E. Graebner. (2007). Building theories from cases: opportunities and challenges, en Academy of Management Journal. Vol. 50, No. 1, 25-32: The Academy of Management

[23]. Farquhar, J.D. (2012). Case Study Research for Business. Sage

[24]. Garduño, S. A. y A. D. Torres R. (2009). El estudio de caso como estrategia metodológica de investigación de las MIPYME. En Primer Congreso Internacional en México Sobre la MIPYME: el Impacto de la Investigación Académica en el Desarrollo de la MIPYME: COCYTEH, Pachuca, Hidalgo.

[25]. Hernández-Pólito, A. (1998). Administración de la Empresa Social Agropecuaria: un estudio de caso sobre los aspectos de la Administración de la Empresa Campesina. Tesis de Maestría en Administración, Universidad de Quebec en Montreal- Universidad Autónoma de Guerrero, enero de 1998. 
[26]. Hernández-Pólito, Antonio. 2002. Análisis Organizacional de las Administradoras de Fondos para el Retiro: un estudio de caso desde la perspectiva del Institucionalismo.

[27]. Malaver R., F. y M. Vargas P. (2004). Hacia una caracterización de los procesos de innovación en la industria colombiana: los resultados de un estudio de casos. En Revista Latinoamericana de Administración, No. 33, CLADEA, Colombia.

[28]. Moilanen, S. (2008). The role of accounting in the management control system: a case study of a family-led firm, en Qualitative Research in Accounting \& Management, Vol. 5, 3:165-183

[29]. Newton, J. (2002). Barriers to effective quality management and leadership: Case study of two academic departments, en Higher Education, Septiembre 2002, Volume 44, 2:185-212

[30]. Piekkari, R. y C. Welch. (2012). Rethinking the Case Study in International Business and Management Research. Edward Elgar Pub

[31]. Siggelkow, N.(2007). Persuasion with case studies. En Academy of Management Journal, 50 (1), 20-24.

[32]. Stake, R. E. (2005). Multiple Case Study Analysis. The Guilford Press

[33]. Suárez-Barraza, M. F. y J. A. Miguel-Dávila. (2011). Implementación del Kaizen en México: un estudio exploratorio de una aproximación gerencial japonesa en el contexto latinoamericano. En Innovar, Revista de Ciencias Administrativas y Sociales, Vol 21, No. 41, jul-sept 2011, Universidad Nacional de Colombia: 19-37.

[34]. Tesis de Doctorado en Administración. Universidad de Québec en Montreal- Universidad Autónoma de Guerrero. México.

[35]. The World Bank; Worldwide Governance Indicators, Country Data Report for Libya, 1996-2011; http://info.worldbank.org/governance/wgi/pdf/c126.pdf; last accessed 20 June 2013

[36]. Urbano, D. N. Toledano y D. Ribeiro-Soriano. (2011). Prácticas de gestión de recursos humanos y desarrollo de nuevos proyectos innovadores: Un estudio de casos en las PYMEs. En Universia Business Review, 1er Trimestre, 2011, ISSN: 1698-5117.

[37]. Walsham, G. (1995). Interpretive case studies in IS research: nature and method, en European Journal of Information Systems, Vol. 4:74-81.

[38]. WHO; Public Health Risk Assessment and Interventions: The Libyan Arab Jamahiriya CivilUnrest; March 2011; WHO/HSE/GAR/DCE/2011.1;

[39]. Woodside, A. (2010). Case Study Research: Theory, Methods and Practice. 1a Ed. Emerald Group

[40]. Yin, R. K. 2002. Case Study Research, Design and Methods, 3a ed. Newbury Park, Sage. Yin, R. K. (2008). Case Study Research: design and methods. 4a Ed. Sage

[41]. Zeiton, Moez; Frontline medicine: inside Libya; The Lancet; 27 August 2011; Vol. 378 Issue 9793; p 756-757; doi:10.1016/S0140-6736(11)61360-3;

[42]. Zenith; Special Libya Healthcare; Business Report Africa, Middle East and Central Asia;September-October 2012 44-67; ISSN : 2193-0333

[43]. Zhu, C. J. y P. J. Dowling. (2000). Managing Human Resources in State-Owned Enterprises in Transitional Economies: A Case Study in the People's Republic of China, en Research and Practice in Human Resource Management, 8, 1: 63-92. 